\title{
Taste-Evoked Responses to Sweeteners in the Nucleus of the Solitary Tract Differ between C57BL/6ByJ and 129P3/J Mice
}

\author{
Stuart A. McCaughey \\ Monell Chemical Senses Center, Philadelphia, Pennsylvania 19104
}

C57BL/6ByJ (B6) and 129P3/J (129) mice have different alleles of Tas1r3, which is thought to influence gustatory transduction of sweeteners, but studies have provided conflicting results regarding differences in sweetness perception between these strains. Single-unit taste-evoked activity was measured in the nucleus of the solitary tract (NST) in anesthetized B6 and 129 mice to address this controversy and to provide the first electrophysiological characterization of this nucleus in mice. Neurons had properties similar to those of NST cells in other species, including mean breadth-of-tuning of $0.8 \pm 0.0$. There were no strain differences in neural responses at 600 or $900 \mathrm{~ms}$ after onset, but, with a $5 \mathrm{~s}$ evoked period, responses to the sweeteners sucrose, maltose, acesulfame-K, SC-45647, and D-phenylalanine were significantly larger in B6 relative to 129 mice. The strains did not differ in their mean response to NaSaccharin, but it evoked an across-neuron pattern of activity that was more similar to that of sucrose and less similar to that of $\mathrm{NaCl}$ in $\mathrm{B} 6$ mice compared with 129 mice. Neurons were classified as sucrose, $\mathrm{NaCl}$, or $\mathrm{HCl}$ responsive, with the former more common in $\mathrm{B} 6$ than 129 mice. Relative to other neurons, sucrose-responsive cells had delayed but more sustained sweetener responses in both strains. The results suggest that B6 mice perceive some sweeteners as more intense, but NaSaccharin as sweeter and less salty, relative to 129 mice. Furthermore, activity evoked by sweeteners includes a phasic response sent to different NST cells than a later tonic response, and only the latter differs between B6 and 129 mice.

Key words: mouse; taste; gustatory; electrophysiology; sweet; NST

\section{Introduction}

Inbred mouse strains vary in their preferences for compounds described as sweet by humans, partly because of allelic variation of Tas1r3 (Reed et al., 2004). This gene is thought to code for a protein, T1R3, that forms a sweetener-binding receptor with the protein T1R2 (Nelson et al., 2001). Haplotypes of Tas1r3 influence binding affinities for sugars in vitro, with more effective binding by the sequence associated with higher sweetener preferences (Nie et al., 2005). However, a complex series of events occurs between receptor binding by taste compounds and changes in brain activity, and only the latter gives rise to perception. Thus, differences in sweetener binding by T1R2/T1R 3 cannot be assumed to cause differences in perceived sweetness.

Two widely studied strains are the C57BL/6ByJ (B6) and 129P3/J (129). The former consume larger volumes of diverse sweeteners in $48 \mathrm{~h}$ tests (Bachmanov et al., 2001) and have larger whole-nerve chorda tympani (CT) responses to sweeteners (Inoue et al., 2001), as one would expect if these compounds taste sweeter to the B6 strain. However, in short-duration paradigms designed to emphasize the role of gustation, B6 mice have smaller

Received Aug. 23, 2006; revised Nov. 20, 2006; accepted Nov. 21, 2006.

This work was supported by National Institutes of Health Grants R03 DC005929 and R01 DK46791. I thank Drs. Alexander Bachmanov, John Glendinning, Michael Tordoff, and Justus Verhagen for their comments on a previous draft of this manuscript.

Correspondence should be addressed to Dr. Stuart McCaughey, Monell Chemical Senses Center, 3500 Market Street, Philadelphia, PA 19104-3308. E-mail: mccaughey@monell.org.

DOl:10.1523/JNEUROSCI.3672-06.2007

Copyright $\odot 2007$ Society for Neuroscience $\quad$ 0270-6474/07/270035-11\$15.00/0 intakes of some concentrations of the sweeteners sucrose and SC-45647 than do 129 mice (Dotson and Spector, 2004; Glendinning et al., 2005). This discrepancy may arise because the large $48 \mathrm{~h}$ intakes of B6 mice are driven by postingestive effects. In addition, the relatively large CT responses of B6 mice do not provide direct insight into sweetness perception per se and may be attributable to greater sensitivity to nonsweet side tastes, given the broad sensitivity of the nerve. Alternatively, the results of the short-term tests could arise from sweeteners tasting less sweet to 129 than B6 mice, combined with greater sensitivity of central reward pathways in 129 mice (Sclafani, 2006a).

Insight can be gained into animals' taste perceptions by measuring the activity of central gustatory neurons in the rostral nucleus of the solitary tract (NST), which receives input from all peripheral taste fibers (Åström, 1953; Hamilton and Norgren, 1984). NST cells in rats code larger stimulus intensity by increasing firing rates (Ganchrow and Erickson, 1970). The neurons are broadly tuned, so a change in the firing rate of one neuron provides little information about the compound responsible (Lemon and Smith, 2006). However, differences in across-neuron patterns of NST activity are closely related to differences in perceived taste quality in rats and hamsters (Doetsch and Erickson, 1970; Smith et al., 1979). Thus, these patterns can be used to make inferences about the animals' perceptions, even if the primary cause of those perceptions is likely to be cortical activity or a neural circuit involving multiple brain areas (Katz et al., 2002).

NST activity has not been monitored previously in mice, but measurement of intakes and peripheral nerve responses in in- 
bred, knock-out, and transgenic mouse strains has provided valuable insight into taste sensation. In the current experiment, NST responses were measured in B6 and 129 mice to determine whether the strains differ in sweetness perception. In addition, the firing properties of mouse NST neurons are described for the first time and compared with those of peripheral gustatory neurons in mice and NST cells in other species.

\section{Materials and Methods}

Subjects. Forty-eight male B6 mice and 40 male 129 mice were used. Recordings were made of the activity of 38 cells from 20 different B6 mice and 41 cells from 18 different 129 mice. Animals were ordered from The Jackson Laboratory (Bar Harbor, ME) and arrived at 6-7 weeks of age. They were housed individually at $\sim 23^{\circ} \mathrm{C}$ on a $12 \mathrm{~h}$ light/dark cycle, and they were given ad libitum access to tap water and standard laboratory chow. They were naive to all test solutions at the time of electrophysiological recording, and thus they could not have experienced the postingestive conditioning effects that have been reported to follow exposure to sweeteners (Sclafani, 2006b). They were 8-32 weeks of age and weighed 20-36 g on the day of recording.

Neural recording. The methods used for electrophysiological recording were adapted from those used previously for NST recording in rats (McCaughey and Tordoff, 2001) with some modifications to accommodate the difference in species. Animals were anesthetized with a mixture of ketamine, xylazine, and acepromazine $(90,20$, and $3 \mathrm{mg} / \mathrm{kg}$, respectively, i.p., with additional doses as necessary), which is an effective anesthetic treatment in mice (Arras et al., 2001). A tracheotomy was performed to prevent suffocation, and a fistula was inserted into the esophagus to avoid ingestion of taste solutions. The head was secured in a nontraumatic head holder modeled after that used in rats to avoid injury to the chorda tympani nerve (Erickson, 1966). A section of skull overlying the cerebellum was removed, and the cerebellum was then aspirated to expose the surface of the medulla. Body temperature was maintained at $33-36^{\circ} \mathrm{C}$ using heating pads, and depth of anesthesia was checked by monitoring breathing rate, heart rate detected by subcutaneous electrodes, and pedal withdrawal reflex.

The activity of single units was isolated using glass microelectrodes filled with $1.6 \mathrm{M}$ potassium citrate and with a tip diameter of $\sim 1 \mu \mathrm{m}$. Cells were identified as being in the NST by the presence of a clear change in firing rate in response to gustatory stimuli. In addition, after the activity of a cell was measured, the electrode position relative to obex was determined. In B6 mice, the mean coordinates of the cells that were recorded were $1.5 \mathrm{~mm}$ anterior to obex, $1.2 \mathrm{~mm}$ lateral to the midline, and $651 \mu \mathrm{m}$ ventral to the surface of the brainstem, and in 129 mice they were $1.7 \mathrm{~mm}$ anterior to obex, $1.3 \mathrm{~mm}$ lateral to the midline, and $627 \mu \mathrm{m}$ ventral to the surface of the brainstem. These coordinates correspond to the location of the rostral NST in neuroanatomy atlases based on mouse strains closely related to those used here (Hof et al., 2000; Paxinos and Franklin, 2001). The signal was amplified, filtered, displayed on an oscilloscope, and recorded onto videotape for off-line analysis. The taped activity was later digitized and converted to ASCII files with a $20 \mathrm{kHz}$ sampling rate.

Presentation of taste stimuli. When the activity of a single taste-sensitive neuron was isolated, responses were recorded to an array of 15 stimuli (Table 1) that included four compounds that served as prototypical sweet ( $500 \mathrm{~mm}$ sucrose), salty (100 mM NaCl), sour $(10 \mathrm{~mm} \mathrm{HCl})$, and bitter $(20$ $\mathrm{mm}$ quinine $\mathrm{HCl}$ ) solutions. Also included in the array were the sugar maltose at $500 \mathrm{~mm}$; the artificial sweeteners $20 \mathrm{~mm}$ acesulfame- $\mathrm{K}, 10 \mathrm{~mm}$

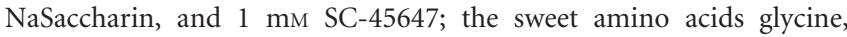
D-phenylalanine, and L-proline, all at $100 \mathrm{~mm}$; the umami stimulus 10 mM disodium $5^{\prime}$-inosine monophosphate (IMP); sour-tasting $10 \mathrm{~mm}$ citric acid; and the bitter salts $100 \mathrm{~mm} \mathrm{CaCl}_{2}$ and $100 \mathrm{~mm} \mathrm{NH}_{4} \mathrm{Cl}$. Here and throughout the paper, descriptions of taste quality are given for stimuli based on previous work (Ninomiya et al., 1984b, 1992; Ninomiya and Funakoshi, 1989; Tanimura et al., 1994; Nakashima et al., 2001; Manita et al., 2006), with the understanding that they must be inferred in nonhuman species such as mice. The term "sweeteners" is used to refer to sucrose, maltose, acesulfame, saccharin, SC-45647, glycine,
Table 1. Taste stimuli that were applied in the experiment, their abbreviations, and mean ( \pm SEM) net responses across all 38 cells in B6 mice and all 41 cells in 129 mice

\begin{tabular}{|c|c|c|c|}
\hline Stimulus & Abbreviation & $\begin{array}{l}\text { Mean net response } \\
\text { (spikes/s) in B6 } \\
\text { mice }\end{array}$ & $\begin{array}{l}\text { Mean net response } \\
\text { (spikes/s) in } 129 \\
\text { mice }\end{array}$ \\
\hline 500 mm sucrose & SUC & $22 \pm 3^{*}$ & $6 \pm 1$ \\
\hline $100 \mathrm{~mm} \mathrm{NaCl}$ & NA & $23 \pm 3$ & $29 \pm 4$ \\
\hline $10 \mathrm{~mm} \mathrm{HCl}$ & $\mathrm{HCl}$ & $17 \pm 3$ & $15 \pm 2$ \\
\hline $20 \mathrm{~mm}$ quinine $\mathrm{HCl}$ & 0 & $16 \pm 2$ & $12 \pm 2$ \\
\hline \multicolumn{4}{|l|}{$10 \mathrm{~mm}$ disodium inosine } \\
\hline 5'-monophosphate & IMP & $13 \pm 1$ & $15 \pm 2$ \\
\hline $500 \mathrm{~mm}$ maltose & MAL & $10 \pm 2^{*}$ & $4 \pm 1$ \\
\hline $20 \mathrm{~mm}$ acesulfame-K & ACE & $19 \pm 2^{*}$ & $5 \pm 1$ \\
\hline $10 \mathrm{~mm}$ NaSaccharin & SAC & $14 \pm 2$ & $10 \pm 2$ \\
\hline $1 \mathrm{~mm}$ SC-45647 & SC & $15 \pm 3^{*}$ & $2 \pm 1$ \\
\hline 100 mm glycine & GLY & $8 \pm 1$ & $5 \pm 1$ \\
\hline 100 mm D-phenylalanine & PHE & $5 \pm 1^{*}$ & $2 \pm 1$ \\
\hline 100 mm L-proline & PRO & $3 \pm 1$ & $2 \pm 1$ \\
\hline $10 \mathrm{~mm}$ citric acid & $\mathrm{Cl}$ & $15 \pm 3$ & $14 \pm 2$ \\
\hline $100 \mathrm{~mm} \mathrm{CaCl}_{2}$ & CA & $15 \pm 3$ & $14 \pm 2$ \\
\hline $100 \mathrm{~mm} \mathrm{NH}_{4} \mathrm{Cl}$ & $\mathrm{NH}$ & $16 \pm 3$ & $13 \pm 2$ \\
\hline
\end{tabular}

${ }^{*} p<0.05$ versus 129 .

D-phenylalanine, and L-proline, and "nonsweet" refers to the other seven stimuli.

The concentrations of stimuli were chosen based on several factors. In general, compounds were used at concentrations that should taste moderately intense to mice based on two-bottle tests with water (Bachmanov et al., 1996, 2001, 2002). Another factor considered was effectiveness at evoking gustatory responses, so when possible concentrations were chosen that evoke CT responses at least one-half as large as the response to $100 \mathrm{mM} \mathrm{NH}_{4} \mathrm{Cl}$ (Inoue et al., 2001). In addition, all of the sweeteners were used at concentrations equal or close to those which are consumed to a greater extent by B6 than 129 mice in $48 \mathrm{~h}$ two-bottle tests with water

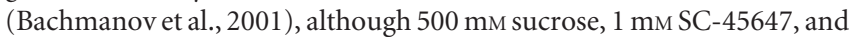
$750 \mathrm{~mm}$ glycine are consumed more avidly by 129 mice in short-term intake tests (Dotson and Spector, 2004; Glendinning et al., 2005). The amino acids were included based on evidence that they taste sweet to mice, but the previous data on them are complex. For example, L-proline but not glycine or D-phenylalanine evokes larger CT responses in B6 than 129 mice (Inoue et al., 2001), and there are significant linkages to Tas $1 r 3$ for D-phenylalanine but not glycine or L-proline in intake tests and CT recordings (Inoue et al., 2004). In $48 \mathrm{~h}$ tests, quinine, IMP, and citric acid are consumed in larger volumes and $\mathrm{NaCl}$ and $\mathrm{CaCl}_{2}$ are consumed in smaller volumes by $\mathrm{B} 6$ mice relative to 129 mice at concentrations equal or close to those used here (Bachmanov et al., 1996, 2000, 2002).

All stimuli were mixed in distilled water, with the exception of the sugars and amino acids, to which $10 \%$ tap water was added to ensure activation of an automatic stimulus onset marker. The stimulus delivery procedure was adapted from that of Chang and Scott (1984). Two milliliters of each stimulus was presented at room temperature and at a rate of $1 \mathrm{ml} / \mathrm{s}$, and it was not rinsed off until at least $5 \mathrm{~s}$ after onset. Stimuli and water rinse were delivered as a spray, and the mouthpiece of the headholder had an opening to allow stimuli to reach the palate; confirmation was made using dyed solution that this method distributed solutions across the entire tongue and throughout the oral cavity. Stimulus presentations were separated by at least a minute and were followed by at least $10 \mathrm{ml}$ of deionized water as a rinse. To avoid adaptation effects, stimuli were given in a semirandom order, in which compounds with similar taste qualities were not presented consecutively.

There were rare instances in which a taste-responsive neuron also had tactile sensitivity, as indicated by a clearly discernable change in firing rate in response to water rinse or air. Such cells were not used in the experiment, so that the responses to stimuli would have only a gustatory component.

Stimuli were presented multiple times when possible and an average of all presentations used. The use of multiple presentations allowed for a 
test of the variability in responding. There were 161 instances in which a stimulus was applied more than once for a given cell in B6 mice, and 123 instances in 129 mice. The net responses for the first and second presentations were highly correlated in both B6 and 129 mice $(r=+0.90$ and +0.88 , respectively) and did not differ from each other using a $t$ test for paired samples in both strains. These results indicate a high degree of stability in the recording preparation.

Analysis. Action potentials were counted from ASCII files using a threshold discrimination method with the Dataview software program (Heitler, 1999). Two strategies were used to confirm that counts included the activity of only one neuron. First, interspike intervals were calculated for all stimulus applications to ensure that there was a clear refractory period. Second, the counted waveforms were overlaid to confirm that their shapes were similar. Action potentials were counted for $3 \mathrm{~s}$ before (spontaneous period) and $5 \mathrm{~s}$ after (evoked period) stimulus onset and expressed as net spikes per second (evoked minus spontaneous), unless indicated otherwise.

Neurons were considered to be taste-responsive and included in the experiment if they gave a significant response to at least one of the 15 stimuli. A response was considered to be significant if the absolute value of the net spikes per second exceeded the SD of the spontaneous firing rate of the cell multiplied by 2.93. This criterion set an $\alpha$ level of 0.003 (or $0.05 / 15)$, two-tailed, to correct for the number of comparisons per cell. Positive responses that met this criterion gave evidence of excitation relative to the spontaneous firing rate, and negative responses that met it gave evidence of inhibition.

Spontaneous firing rates were compared between strains using $t$ tests. The breadth-of-tuning of each cell was calculated using a standard metric (Smith and Travers, 1979). The maximum tuning value of 1 would represent a neuron that gives equal responses to representative sweet, salty, sour, and bitter stimuli, and the minimum of zero would occur if a neuron responded to only one of those four stimuli. Breadth-of-tuning values were compared between strains using Mann-Whitney $U$ tests because of the distributions being negatively skewed in both strains. Net responses were compared between strains using two-way mixed ANOVAs with strain and stimulus as factors, followed by post hoc $t$ tests when appropriate to compare responses to individual stimuli between strains.

Stimuli were compared with each other within a strain by calculating the Pearson correlation coefficients between each one's across-neuron pattern of responding and those of the other stimuli; multidimensional scaling was then performed on the correlation matrix that resulted, and a multidimensional space was generated in which stimuli with similar across-neuron patterns were located close to each other. For some of the spaces that were generated, the use of three dimensions instead of two would have substantially reduced the statistical stress that resulted, but for most of them this was not the case, and so two dimensions were used for all for the sake of consistency. Corresponding correlations were compared between strains using a $Z$ test for independent correlation coefficients.

Neurons within a strain were compared with each other using cluster analysis based on their profiles of responding across the four prototypical stimuli. The distance measure used was 1 minus the Pearson correlation coefficient between the response profiles of the cells, and an "unweighted pair-group average" amalgamation rule was used. The resulting dendrograms were then examined and subgroups of neurons determined visually, followed by comparisons between subgroups within a strain using ANOVAs and post hoc $t$ tests to confirm that they differed from each other on appropriate stimuli. The appropriateness of the subgroups was also confirmed by plotting linkage distance versus amalgamation steps for the cluster analysis and looking for a sudden jump in the distance at the step at which the clusters joined. Net responses in subgroups were compared between strains using ANOVAs with strain and stimulus as factors, followed by post hoc $t$ tests to determine the stimuli on which they differed. There was a large difference between the strains in the number of S-cells, but tests of homogeneity of variance confirmed that it was appropriate to compare strains using an ANOVA and $t$ tests.

Temporal patterns of net responses were examined for each stimulus by constructing poststimulus time histograms (PSTHs) in which spikes across the $5 \mathrm{~s}$ evoked period were distributed into $100 \mathrm{~ms}$ bins. Bins were averaged across all cells, regardless of whether they responded significantly. Temporal patterns were compared between strains using two-way ANOVAs with time as a repeated-measures factor. Only the first 25 bins ( $2500 \mathrm{~ms}$ ) of the response were used for these tests, because there was minimal temporal variation after this period for all stimuli. A significant strain by time interaction in the ANOVA was taken as evidence of a difference in the temporal pattern of response. Based on the outcome of these comparisons, some tests using mean firing rates were repeated using evoked periods other than $5 \mathrm{~s}$. These analyses were conducted as described above, except for the period over which evoked spikes were counted, and are identified in the text.

Statistics were performed using the Statistica software package. Values are presented as means \pm SEM. A criterion of $p<0.05$ was used for significance.

\section{Results}

\section{Spontaneous activity}

In B6 mice, the mean ( \pm SEM) spontaneous firing rate across all cells was $5.0 \pm 0.5$ spikes/s. In 129 mice, the mean spontaneous rate across all cells was $8.1 \pm 0.7$ spikes/s, which was significantly faster than the rate for B6 mice $\left(t_{(77)}=3.44\right.$; $\left.p<0.001\right)$. The mean rates for both groups are slower than is typically found for NST cells in rats (Verhagen et al., 2003) and hamsters (Smith and $\mathrm{Li}, 1998$ ), but faster than the mean reported for monkeys (Scott et al., 1986). In addition, the mean spontaneous rates of B6 and 129 mice were faster than the means of 2.5-2.7 spikes/s reported for CT fibers of C57BL/6CrSlc, BALB/cCrSlc, and $\mathrm{C} 3 \mathrm{H} / \mathrm{HeSlc}$ mice (Ninomiya et al., 1984a).

\section{Evoked responses}

Table 1 lists the mean responses across all cells for each stimulus. NST cells in the B6 strain gave significantly larger responses than did those in the 129 strain to sucrose, maltose, acesulfame, SC45647, and D-phenylalanine (effect of strain, $F_{(1,77)}=5.9, p=$ 0.02 ; strain by stimulus interaction, $F_{(14,1078)}=6.0, p<0.001$; $p<0.01$ in post hoc $t$ tests). Significant inhibitory responses were observed rarely, as is the case for NST cells in rats and monkeys (Scott et al., 1986; Nakamura and Norgren, 1993). There were no instances in B6 mice and only four in 129 mice.

Of the 38 cells that were recorded in $\mathrm{B} 6$ mice, 36 gave significant responses to more than one of the prototypical stimuli, as did 30 of the 41 cells in 129 mice. The mean breadth-of-tuning across all cells was $0.80 \pm 0.02$ in B6 mice and $0.76 \pm 0.03$ in 129 mice. Although the typical cell was broadly tuned, a small number of cells were more selective in their responsiveness, with minimum breadth-of-tuning values of 0.54 and 0.27 in B6 and 129 mice, respectively. The two strains did not differ from each other, and the mean tuning of the cells is similar to values reported for NST cells in rats and hamsters (Travers and Smith, 1979; Verhagen et al., 2003), but larger than values of $0.28-0.41$ reported for peripheral nerves in $\mathrm{C} 57 \mathrm{BL} / 6 \mathrm{CrSlc}, \mathrm{BALB} / \mathrm{cCrSlc}$, and $\mathrm{C} 3 \mathrm{H} /$ HeSlc mice (Ninomiya et al., 1984a). The activity of two neurons that responded to three of the prototypical stimuli is shown in Figure 1.

\section{Across-neuron patterns of activity}

Within each strain, stimuli were compared with each other based on their across-neuron patterns of activity, and the resulting multidimensional spaces are shown in Figure 2. Stimuli thought to evoke the same taste quality in mice generally fell into groupings with each other. In both strains, $\mathrm{NaCl}$ and sucrose were located apart from each other, and there was a separate grouping with the acids, quinine, $\mathrm{CaCl}_{2}$, and $\mathrm{NH}_{4} \mathrm{Cl}$. In $\mathrm{B} 6$ mice, the sugars and artificial sweeteners were all located close to each other, but in 129 
mice they were more spread out, with saccharin located closer to $\mathrm{NaCl}$ than to sucrose. In both strains, the sweet amino acid glycine was located close to sucrose. D-Phenylalanine and L-proline were not located close to any of the other compounds, although this may have occurred because they evoked small responses, which would tend to lower correlations between their across-neuron patterns and those of other stimuli. IMP was not placed near any of the prototypical stimuli, an appropriate location for an umami compound. However, it was also about halfway between sucrose and $\mathrm{NaCl}$ in both strains, and it was close to saccharin in 129 mice, as one would expect for a compound tasting about equally salty and sweet. The disodium salt of IMP was used, which likely lent some saltiness to its taste, and there is a report that conditioned aversions generalize between IMP and sucrose in rats (Yamamoto et al., 1991), although not in mice (Nakashima et al., 2001).

The B6 and 129 mice appeared to differ in their locations of the artificial sweeteners relative to the prototypical stimuli, and stimuli were generally more spread out in the space for 129 mice than in the space for B6 mice. The nature of multidimensional scaling makes it inappropriate to compare the spaces on the absolute distances between pairs of stimuli, but the similarity between two stimuli can be compared between $\mathrm{B} 6$ and 129 mice by testing whether there was a significant strain difference in the individual correlations that were used to generate the spaces (Table 2). The across-neuron patterns of acesulfame, saccharin, and SC-45647 were significantly more similar to the pattern of sucrose in B6 compared with 129 mice, and the pattern of saccharin was also less similar to that of $\mathrm{NaCl}$ in the $\mathrm{B} 6$ strain. These significant differences were not part of a generalized strain difference in how similar stimuli were to each other. The only other correlations that differed between the strains, apart from the four just mentioned, were those between sucrose and $\mathrm{NaCl}$ and between $\mathrm{HCl}$ and $\mathrm{CaCl}_{2}$.

\section{Division into neural subgroups}

Figure 3 shows the results of categorizing the cells within each strain using cluster analysis based on their response profiles. In both strains, three subgroups of cells were evident that tended to be most responsive to sucrose, $\mathrm{NaCl}$, or $\mathrm{HCl}$ (S-, $\mathrm{N}$-, and $\mathrm{H}$-cells, respectively), as is typically found for NST cells in rats and hamsters (Smith et al., 1983; Nakamura and Norgren, 1993). Figure 4 shows the net responses of individual neurons in the three subgroups, and mean responses of subgroups are shown in Figure 5. S-cells were more prevalent in B6 than 129 mice, whereas the opposite was true for $\mathrm{N}$-cells, and a $\chi^{2}$ analysis confirmed that the distributions of cells into the three subgroups differed signifi-
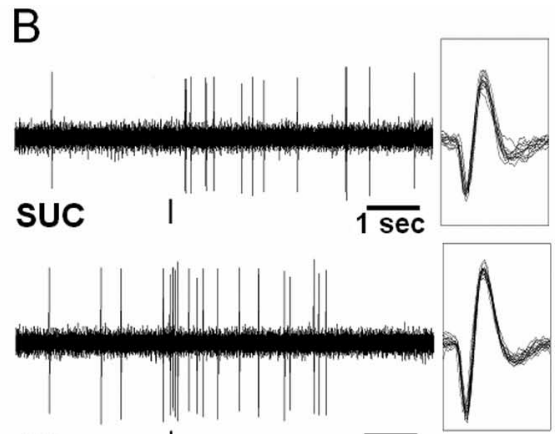

NA
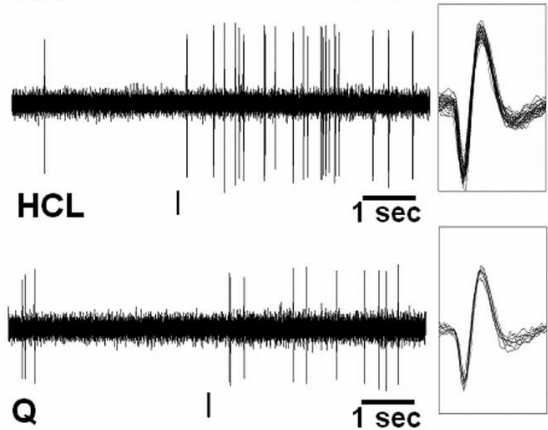

$\sqrt{\mathrm{sec}}$

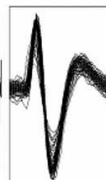

$1 \mathrm{sec}$

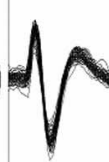

$\overline{1 \mathrm{sec}}$
B6

Two-dimensional spaces resulting from multidimensional scaling and showing the similarity of stimuli based on their across-neuron patterns of activity in B6 (left) and 129 (right) mice. An evoked period of $5 \mathrm{~s}$ was used. Abbreviations are as in Table 1.

cantly between the strains $\left(\chi^{2}=23.2 ; p<0.05\right)$. Previous work in hamsters has shown that S-cells in the NST are necessary for the generation of a unique across-neuron pattern of responding for sweeteners (Smith et al., 1983). In the current study, the small number of S-cells in 129 mice was adequate to allow for a grouping of five sweeteners in the multidimensional space that was generated (Fig. 2).

The spontaneous firing rates of $\mathrm{S}$-, $\mathrm{N}$-, and $\mathrm{H}$-cells are also shown in Figures 4 and 5. N-cells of 129 mice had significantly faster spontaneous rates than did $\mathrm{N}$-cells of B6 mice $\left(t_{(35)}=2.8\right.$; $p=0.008)$, but the rates of S- and H-cells did not differ between strains. All of the significant inhibitory responses, which occurred in two cells for SC-45647 and in one cell each for acesulfame and D-phenylalanine, were observed in N-cells of 129 mice (Fig. 4).

Corresponding subgroups were compared between strains, and a significant difference was found for $\mathrm{H}$-cells (effect of strain, 
Table 2. Pearson correlation coefficients between across-neuron patterns of all stimuli and those of prototypical stimuli in B6 and 129 mice

\begin{tabular}{|c|c|c|c|c|c|c|c|c|}
\hline & \multicolumn{2}{|l|}{ SUC } & \multicolumn{2}{|l|}{ NA } & \multicolumn{2}{|l|}{$\mathrm{HCl}$} & \multicolumn{2}{|l|}{ Q } \\
\hline & B6 & 129 & B6 & 129 & B6 & 129 & B6 & 129 \\
\hline SUC & +1.00 & +1.00 & $-0.33^{*}$ & +0.13 & -0.14 & +0.19 & +0.06 & +0.08 \\
\hline NA & $-0.33^{*}$ & +0.13 & +1.00 & +1.00 & +0.61 & +0.49 & +0.33 & +0.37 \\
\hline $\mathrm{HCl}$ & -0.14 & +0.19 & +0.61 & +0.49 & +1.00 & +1.00 & +0.73 & +0.60 \\
\hline Q & +0.06 & +0.08 & +0.33 & +0.37 & +0.73 & +0.60 & +1.00 & +1.00 \\
\hline IMP & +0.43 & +0.53 & +0.56 & +0.78 & +0.49 & +0.48 & +0.24 & +0.31 \\
\hline MAL & +0.73 & +0.82 & -0.06 & +0.22 & +0.16 & +0.25 & +0.15 & +0.10 \\
\hline$A C E$ & $+0.90^{*}$ & +0.65 & -0.30 & +0.13 & -0.03 & +0.40 & +0.11 & +0.40 \\
\hline SAC & $+0.78^{*}$ & +0.52 & $-0.07^{*}$ & +0.67 & +0.04 & +0.28 & +0.13 & +0.22 \\
\hline SC & $+0.86^{*}$ & +0.67 & -0.42 & -0.02 & -0.25 & +0.11 & +0.02 & +0.16 \\
\hline GLY & +0.71 & +0.59 & -0.12 & +0.09 & +0.05 & +0.43 & +0.08 & +0.21 \\
\hline PHE & +0.47 & +0.29 & +0.17 & +0.04 & +0.31 & +0.46 & +0.39 & +0.28 \\
\hline PRO & -0.05 & +0.38 & +0.20 & +0.10 & +0.51 & +0.13 & +0.54 & +0.27 \\
\hline $\mathrm{Cl}$ & -0.12 & +0.25 & +0.63 & +0.47 & +0.91 & +0.86 & +0.67 & +0.50 \\
\hline CA & -0.16 & +0.18 & +0.48 & +0.45 & $+0.86^{*}$ & +0.68 & +0.78 & +0.83 \\
\hline $\mathrm{NH}$ & -0.23 & +0.21 & +0.61 & +0.53 & +0.91 & +0.81 & +0.62 & +0.70 \\
\hline
\end{tabular}

Abbreviations are as in Table 1.

${ }^{*} p<0.05$ versus 129 .

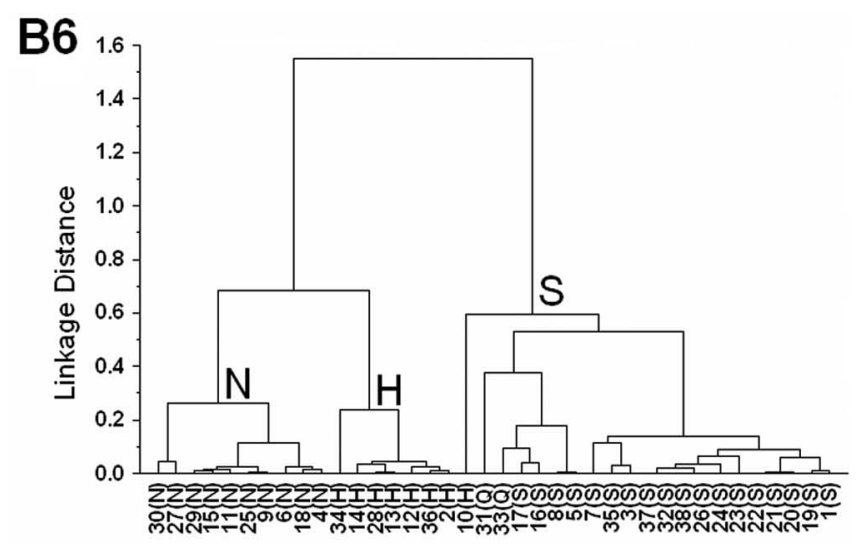

129

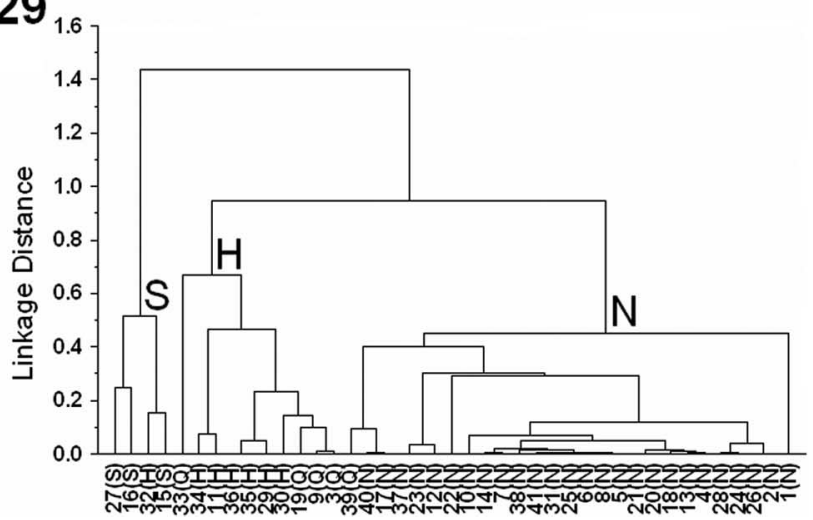

Figure 3. Dendrograms resulting from classification of neurons using cluster analysis in B6 (top) and 129 (bottom) mice. Cells were compared with each other based on their profiles of responding across the prototypical stimuli, and they are labeled underneath with cell numbers and, in parentheses, whether they responded most effectively to sucrose $(\mathrm{S}), \mathrm{NaCl}(\mathrm{N}), \mathrm{HCl}(\mathrm{H})$, or quinine (Q). The branch points defining $\mathrm{S}-, \mathrm{N}$-, and $\mathrm{H}$-cells are also indicated by the appropriate letter. In B6 mice, there were 21 S-cells, $10 \mathrm{~N}$-cells, and $7 \mathrm{H}$-cells, and in 129 mice, there were $4 \mathrm{~S}$-cells, $27 \mathrm{~N}$-cells, and $10 \mathrm{H}$-cells.

$F_{(1,15)}=6.8, p=0.02$; strain by stimulus interaction, $F_{(14,210)}=$ $2.3, p=0.006)$, and in post hoc tests responses were significantly larger in $\mathrm{B} 6$ mice to sucrose, $\mathrm{NaCl}$, maltose, acesulfame, saccharin, and $\mathrm{NH}_{4} \mathrm{Cl}$ (Fig. 5) $\left(t_{(15)} \geq 3.6, p<0.05\right.$ in all cases). The mean responses of $\mathrm{N}$-cells did not differ between strains. A sig- nificant strain by stimulus interaction was found for S-cells $\left(F_{(14,322)}=66.8 ; p=\right.$ $0.002)$, but there were no significant differences in post hoc tests, although there was a trend $(0.05<p<0.10)$ toward larger responses to acesulfame and SC45647 and smaller responses to citric acid in S-cells of B6 mice.

Within each strain, S-cells were especially likely to give larger responses to IMP than to $\mathrm{NaCl}$. This occurred for 14 of the 21 S-cells in B6 mice and all 4 S-cells in 129 mice. In contrast, IMP responses were never larger than $\mathrm{NaCl}$ responses in $\mathrm{N}$ - or $\mathrm{H}$-cells of B6 mice, and they were for only one $\mathrm{N}$-cell and two $\mathrm{H}$-cells in 129 mice. These data do not necessarily mean that IMP tastes sweet to mice, but they suggest that sodium made relatively little contribution to IMP responses in S-cells compared with responses in $\mathrm{N}$ - or $\mathrm{H}$-cells. There is no way to know the exact size of the sodium-dependent component of the response to IMP for a given cell, but it was estimated to be $50 \%$ of the response of the cell to $\mathrm{NaCl}$, based on the ratio of responses to 10 and $100 \mathrm{~mm} \mathrm{NaCl}$ in the CT of C57BL/6J mice (Frank and Blizard, 1999). This component was subtracted from the total IMP response to yield an estimated sodium-independent component for each cell. S-cells had significantly larger sodium-independent components than did N-or $\mathrm{H}$-cells within each strain $\left(t_{(12-29)}>3.3, p<0.006\right.$ in all cases), but the strains did not differ from each other in a comparison across all cells.

\section{Temporal patterns of responding}

Figure 6 shows mean responses over time in the form of PSTHs. In both strains, nonsweeteners evoked temporal patterns with a phasic response portion that peaked within $500 \mathrm{~ms}$ after stimulus onset and that was followed by a lower level of tonic responding. $\mathrm{NaCl}$ was the only nonsweet compound to evoke different temporal patterns in the two strains $\left(F_{(24,1848)}=1.9 ; p=0.004\right)$. Among the sweeteners, temporal response patterns differed significantly between the strains for sucrose, maltose, saccharin, SC45647, D-phenylalanine, and L-proline $\left(F_{(24,1752-1848)}>1.7, p<\right.$ 0.02 in all cases). Of the total response evoked across $5 \mathrm{~s}$ within a strain, a larger proportion of it occurred during an initial phasic portion in 129 mice than in B6 mice for these stimuli. The strain difference was especially clear for sucrose and SC-45647, which stimulated little activity until $600-700 \mathrm{~ms}$ after stimulus onset in B6 mice.

However, temporal patterns averaged across a particular neural subgroup were generally similar in the two strains for sweeteners (Fig. 7) (amino acids are not shown because of their small responses). The only significant strain by time interactions were for D-phenylalanine and L-proline in S-cells and acesulfame and D-phenylalanine in H-cells $\left(F_{(24,336-552)}>1.9, p<0.005\right.$ in all cases). If patterns for sugars and artificial sweeteners are compared between subgroups within B6 mice, differences can be observed between S-cells, which showed little responsiveness until $\sim 600$ ms after stimulus application, and N- and H-cells, which evoked responses that had an earlier onset but had peaked and declined greatly by $600 \mathrm{~ms}$. In 129 mice, there were similar response delays for most sweeteners in S-cells relative to $\mathrm{N}$ - or $\mathrm{H}$-cells, but the small number of S-cells meant that they contrib- 
uted little to the patterns averaged across all neurons shown in Figure 6.

The PSTHs reinforce that the results of statistical tests may depend on the time period over which spikes are counted (Katz et al., 2001). Therefore, some comparisons were repeated using the same methods, but with only portions of the $5 \mathrm{~s}$ evoked period. The use of only the first 600 or 900 $\mathrm{ms}$ of activity after onset resulted in no difference between the strains in their net responses across all cells (effect of strain and strain by stimulus interaction, NS). There was a significant strain difference with the first $1200 \mathrm{~ms}$ (strain by stimulus interaction, $\left.F_{(14,1078)}=2.2, p=0.008\right)$, which was attributable to larger responses to acesulfame and sucrose in B6 mice $\left(t_{(77)}\right.$ $>2.6, p<0.01$ in both cases). Spikes were also counted between $600 \mathrm{~ms}$ and $5 \mathrm{~s}$ after onset, which resulted in strain differences similar to those found with the entire $5 \mathrm{~s}$ period, with significantly larger responses to sucrose, maltose, acesulfame, SC45647, glycine, and D-phenylalanine in B6 mice (effect of strain, $F_{(1,77)}=9.8, p=$ 0.002 ; strain by stimulus interaction, $F_{(14,1078)}=7.0, p<0.001 ; t_{(77)}>2.2, p<$ 0.03 in post hoc tests).

Figure 8 shows net responses to the sweeteners in individual cells using only a phasic response portion, defined as the initial $600 \mathrm{~ms}$ based on Figures 6 and 7 . This period provided adequate time for cells to respond, as indicated by the large number of significant values. In fact, nearly one-half of the N-cells (17 of 37 across both strains) responded significantly to sucrose, and some neurons gave a net response to sucrose of $>50$ spikes/s. However, the across-neuron patterns of activity evoked by the sweeteners differed substantially from those observed with a 5 s evoked period (Fig. 4). This was reflected in Pearson correlation coefficients between the across-neuron pattern of a sweetener during the phasic period and its pattern during a tonic period $(600 \mathrm{~ms}$ to $5 \mathrm{~s})$. The correlation between the patterns of sucrose during these periods was -0.06 and +0.35 in B6 and 129 mice, respectively, and correlations for other sweeteners were all less than +0.48 , except for that of saccharin in 129 mice. In contrast, correlations between phasic and tonic patterns were greater than +0.50 for the nonsweet compounds in all cases, except for that of quinine in 129 mice. Thus, low correlations were not an inherent outcome of correlating response profiles during these two periods.

A $600 \mathrm{~ms}$ evoked period resulted in a larger number of significant excitatory responses to sweeteners in $\mathrm{N}$ - and $\mathrm{H}$-cells relative to the $5 \mathrm{~s}$ period, but there were also more significant inhibitory responses in $\mathrm{N}$-cells with the $600 \mathrm{~ms}$ period (Fig. 8). In B6 mice, there was one significant inhibitory response to proline and one 은 40 ations are as in Table 1).
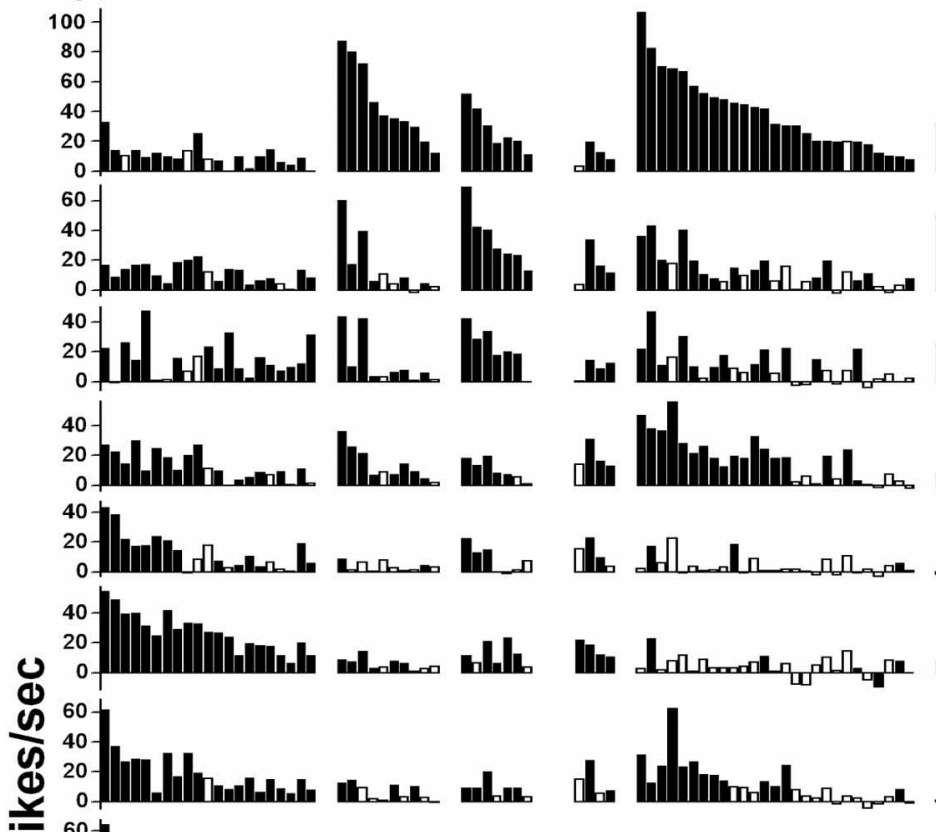

ㄴ. 16. In

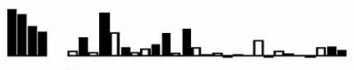
ـ SUC . r.

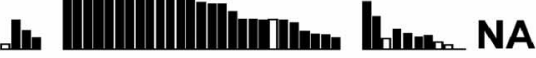

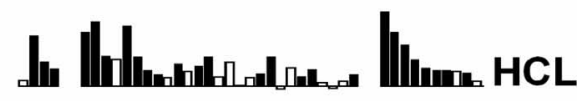

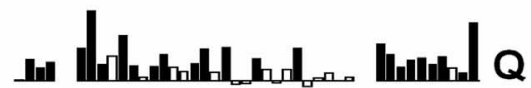
|l||

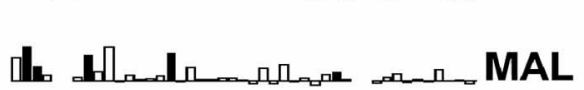

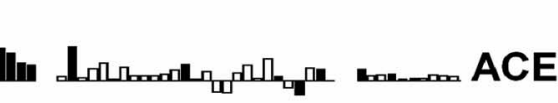
L. Inlmimat SAC PRO

Figure 4. Across-neuron patterns displaying net responses to the 15 stimuli and spontaneous firing rates in individual neurons in $\mathrm{B} 6$ (left) and 129 (right) mice. For each strain, $\mathrm{S}-, \mathrm{N}-$-, and $\mathrm{H}$-cells are placed together and in descending order of their responses to sucrose, $\mathrm{NaCl}$, and $\mathrm{HCl}$, respectively. The filled bars indicate that the response reached the criterion for significant excitation or inhibition, whereas the open bars did not. Responses are based on a $5 \mathrm{~s}$ evoked period. Stimuli are labeled on the right (abbrevi- 


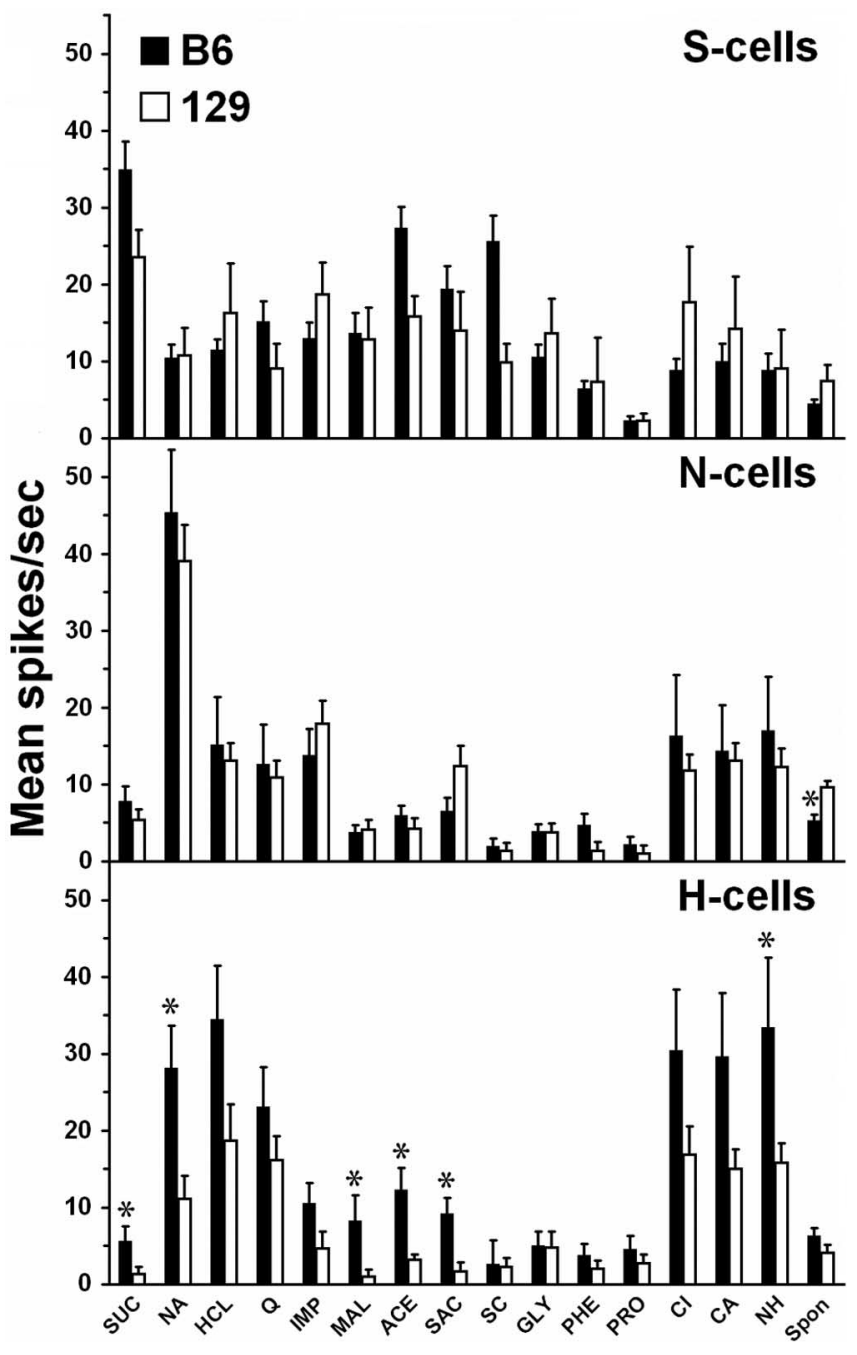

Figure 5. Mean ( \pm SEM) net responses to the 15 stimuli and spontaneous firing rates in subgroups of neurons with different response profiles in B6 (filled bars) and 129 (open bars) mice. Responses represent the average across a particular subgroup, and thus they do not reflect the fact that the strains differed in the percentage of cells in each subgroup. Top, S-cells; middle, $\mathrm{N}$-cells; bottom, $\mathrm{H}$-cells. ${ }^{*} p<0.05$ versus 129 mice. Abbreviations are as in Table 1.

response to water or air applied between stimuli. However, this criterion does not eliminate the possibility of some contribution of tactile effects. If the cells included in the experiment had a major tactile component, then they should have responded significantly to all 15 stimuli, especially during the first $600 \mathrm{~ms}$. Although, of the 79 cells in both strains, only one gave significant responses to all stimuli, and only four responded significantly to 14 of 15 . These data suggest that touch or temperature did not make a major contribution to the responses of cells at $600 \mathrm{~ms}$, although a minor contribution cannot be ruled out.

The correlations between phasic and tonic response profiles within a strain indicated that these two periods may be independent for sweeteners. Furthermore, phasic responses were similar in mouse strains known to differ in sweetener transduction mechanisms and intakes, and phasic responses tended to be largest for those sweeteners thought to have the largest nonsweet side tastes. These data raise the question of whether only tonic responses, and not phasic responses, are associated with the perception of sweetness. To address this issue, across-neuron patterns were examined over a $600 \mathrm{~ms}$ evoked period using multidimensional scaling. A $900 \mathrm{~ms}$ evoked period was also used, based on previous work that rats can sometimes recognize taste stimuli within $600 \mathrm{~ms}$, but sometimes need slightly longer (Scott, 1974). Spaces based on $600 \mathrm{~ms}$ of response time provided a much poorer relationship to stimulus quality than had been obtained with the $5 \mathrm{~s}$ evoked period (Fig. $9 A, B$ ). This was true not only for the sweeteners, but also for other compounds, with $\mathrm{NaCl}$ located close to the sour and bitter stimuli. With a $900 \mathrm{~ms}$ evoked period, the relative locations of most stimuli were more similar to the $5 \mathrm{~s}$ locations in B6 mice (Fig. 9C), but in 129 mice they differed from the $5 \mathrm{~s}$ locations and were poorly related to the taste qualities of stimuli (Fig. 9D).

\section{Discussion}

Most properties of NST cells in B6 and 129 mice were similar to those for this area in other species. Significant inhibitory responses were uncommon. Relative to values for the mouse CT, spontaneous firing rates were faster and neurons were more broadly tuned, suggesting that peripheral fibers with different response profiles converge onto a single NST cell.

Mean responses across all neurons were larger in B6 than 129 mice for sucrose, maltose, acesulfame, SC-45647, and D-phenylalanine, and B6 mice had more S-cells than did 129 mice. The strains vary across many genes, but Tas $1 r 3$ is likely to contribute to these differences, given its linkages to behavioral and neural responses to sweeteners in hybrids of B6 and 129 mice (Inoue et al., 2004). Thus, a component of the strain differences in NST responses likely originates with less effective binding of sweeteners to the T1R2/T1R3 receptor in 129 mice, causing smaller intracellular signals in receptor cells and smaller peripheral nerve responses compared with B6 mice. Consistent with this, 129 mice have smaller CT responses to sucrose, maltose, acesulfame, and SC-45647 than do B6 mice (Inoue et al., 2001). This mechanism also explains why there were fewer sucroseresponsive cells in 129 mice. Although, it is interesting, that 129 mice had a small number of S-cells, despite having an ineffective form of T1R2/T1R3. Possible explanations include amplification of a small signal generated after activation of T1R2/T1R3 or involvement of another transduction mechanism.

More detailed analyses provided additional insight. The strains had similar mean responses to saccharin, although this compound evokes a smaller CT response in 129 compared with B6 mice (Inoue et al., 2001). However, analyses of across-neuron patterns of activity, which were similar for stimuli thought to evoke similar taste qualities, revealed strain differences for saccharin. In B6 mice, the across-neuron pattern of saccharin was more similar to that of sucrose and less similar to that of $\mathrm{NaCl}$ than it was in 129 mice. Thus, the strains had the same overall level of responding to saccharin, but differed in which neurons responded most effectively, suggesting that saccharin tastes sweeter and less salty to B6 mice. Previously, the response pattern to saccharin across NST neurons was correlated more highly with that to sucrose and less highly with that to $\mathrm{NaCl}$ in saccharinpreferring rats than in rats that avoided saccharin (Giza et al., 1996).

In multidimensional spaces of both strains, sucrose, maltose, acesulfame, and SC-45647 were located closest to each other and apart from nonsweet stimuli, so the larger responses to them in B6 mice presumably caused a larger intensity sweet signal. However, acesulfame and SC-45647 also evoked across-neuron patterns that were more like that of sucrose in $\mathrm{B} 6$ mice, so these compounds may taste more purely sweet to them than they do to 129 mice.

Although there was evidence that saccharin tastes more salty 
to 129 than B6 mice, it is unlikely that this was attributable to differences in sodium transduction, because the strains had similar responses to $\mathrm{NaCl}$. One possible explanation is that, counterintuitively, the difference in saltiness arose solely because of strain differences in sweetness transduction, combined with a similar inhibition of salt-sensitive cells by sucrose-responsive ones in both strains. The strains have different alleles of Tas1r3, which has been linked to differences between B6 and 129 mice in CT responses to saccharin (Inoue et al., 2004). Furthermore, although significant inhibitory responses were observed rarely, almost all occurred in $\mathrm{N}$-cells after application of a sweetener, which suggests that sucrose-responsive cells, either in the NST or in other central or peripheral locations, can inhibit salt-responsive cells. Together, these mechanisms would mean that less effective activation of sweetnessrelated transduction mechanisms by saccharin in 129 mice would result in less inhibition of salt-sensitive cells and a larger response to the sodium component of saccharin compared with B6 mice. The end result would be a greater tendency for responses to saccharin and $\mathrm{NaCl}$ to be large in the same neurons and for their acrossneuron patterns to be highly correlated in 129 mice relative to $\mathrm{B} 6$ mice, as was found here (Table 2, Fig. 4). Additional work will be needed to test this hypothesis.

Analysis of temporal patterns of sweetener responses provided evidence that they occurred in two independent stages. An initial phasic portion, defined as 600 $\mathrm{ms}$, did not differ between the strains and was adequate to cause significant increases over baseline firing, but not preferentially in neurons classified as sugar responsive based on their $5 \mathrm{~s}$ responses (S-cells). A later tonic portion differed between the strains and affected primarily S-cells. The phasic response was similar in strains with different Tas1r3 alleles, suggesting that this response portion does not involve the T1R2/T1R3 receptor. Thus, these two stages of sweetener responses seem to be associated with divergent neural pathways that originate with different transduction mechanisms and that are sent to different NST cells within each strain. Although the phasic response may generate perceptions of sweetness, it could be responsible solely for the nonsweet side tastes inevitably associated with sweeteners; across-neuron patterns based on phasic responses could not resolve this question, because they were poor predictors of taste quality in general. Regardless, the phasic response to sweeteners provides a cue that could drive ingestion by Tas1r3-null mice, especially in longterm tests involving postingestive conditioning (Damak et al., 2003).

S-cells may have given delayed responses to sweeteners be-

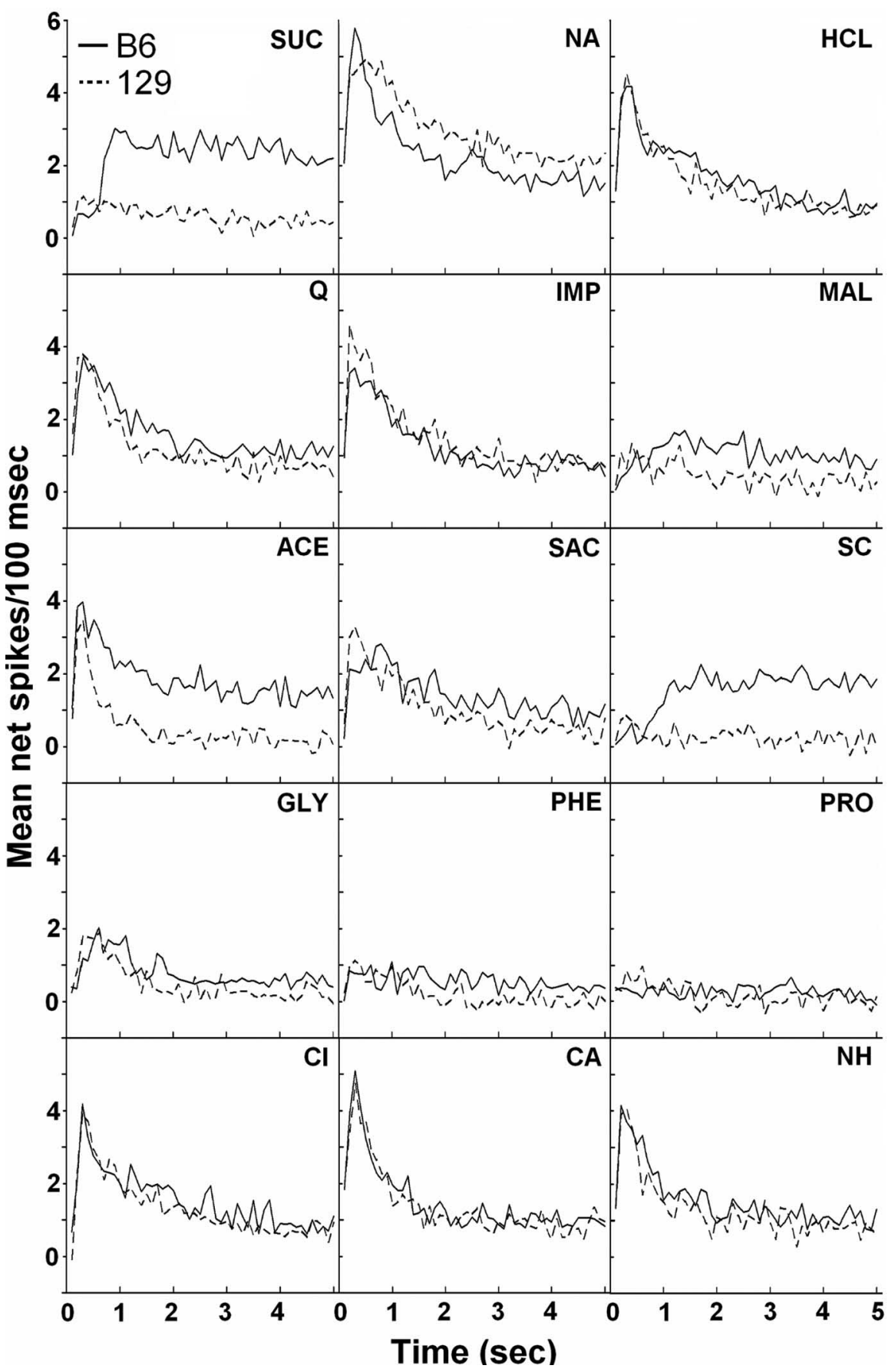

Figure 6. Poststimulus histograms showing temporal patterns of responding to the 15 stimuli in the first $5 \mathrm{~s}$ after application for B6 (solid lines) and 129 (dashed lines) mice. Values for each bin represent net spikes summed across 100 ms and averaged across all neurons, and stimulus onset was at time 0 . Abbreviations are as in Table 1.

cause of inhibition from $\mathrm{N}$ - or $\mathrm{H}$-cells, or a similar mechanism may have occurred in the periphery, given that the onset in S-cells coincided with the decline of the other subgroups in responding. The response delay may also result from some process that amplifies the initial signal generated by sweeteners, because large but delayed responses to sweeteners were observed in a few cells in 129 mice, despite their ineffective form of the T1R2/T1R3 receptor. In addition, the involvement of G-proteins in sweetener transduction may contribute to the delayed response, although no delay was observed for responses to quinine and IMP, which are also thought to be G-protein mediated. 


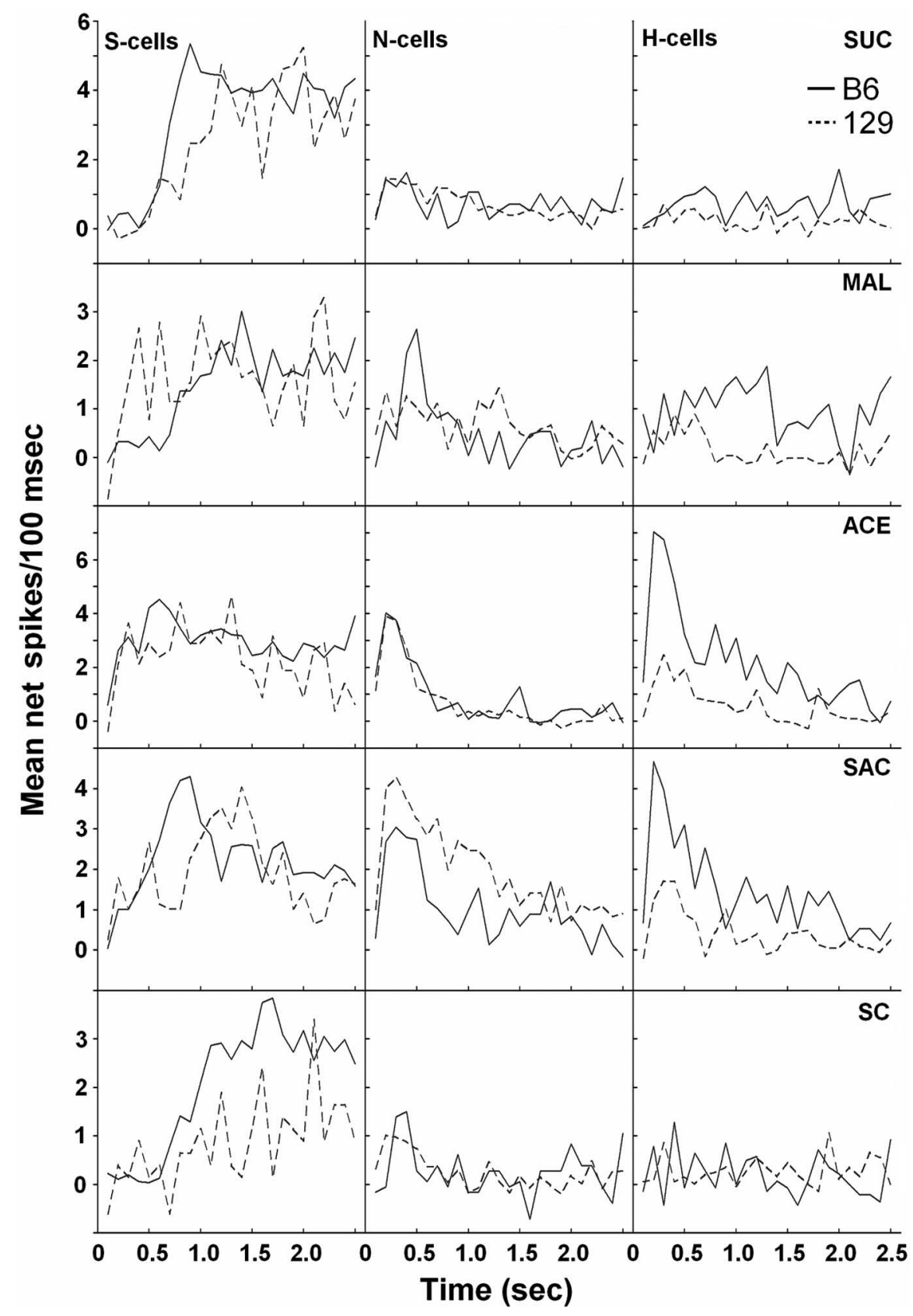

Figure 7. Poststimulus histograms comparing temporal responses in subgroups of neurons between B6 (solid lines) and 129 (dashed lines) mice for the sugars and artificial sweeteners. Values represent net spikes averaged across all cells within a subgroup in 100 ms bins, and stimulus onset was at time 0 . Only the first $2.5 \mathrm{~s}$ of the responses are shown, because there was minimal temporal variation in all responses after that period. Subgroups are arranged in columns and are labeled at the top, and stimuli are arranged in rows and labeled on the right (abbreviations are as in Table 1). Note that the scale for the $y$-axis differs between stimuli.

The strain differences in neural measures that correlate with taste quality and intensity perceptions (see above) likely contribute to the greater consumption of sugars and artificial sweeteners by $\mathrm{B} 6$ than 129 mice in $48 \mathrm{~h}$ tests, although this does not preclude a role for postingestive factors. None of the analyses conducted, even those involving restricted time periods, explains why the results of long- and short-term tests differ for sucrose and SC45647 or why these compounds are consumed more avidly by 129 than B6 mice in short-terms tests. Thus, the latter result must arise from strain differences in some factor other than taste perception.
Glycine, D-phenylalanine, and Lproline were included based on previous evidence that they taste sweet and are consumed in larger volumes by B6 than 129 mice. D-Phenylalanine evoked a larger response across all cells in B6 mice and presumably tasted more intense to them, but the data provided poor insight into the perceived quality of D-phenylalanine and L-proline, possibly because these compounds have complex tastes, although their ineffectiveness as stimuli could also be responsible. Glycine, which appeared to taste sweet to both strains, evoked a similar response in $\mathrm{B} 6$ and 129 mice. Thus, there was not clear evidence that the amino acid stimuli taste more purely or intensely sweet to B6 mice than to 129 mice, as was the case for the sugars and artificial sweeteners, so some nongustatory factor may cause larger consumption of them in B6 mice relative to 129 mice.

B6 and 129 mice had similar mean responses across all cells to nonsweet compounds, and other analyses cannot explain why the strains differ on $48 \mathrm{~h}$ intakes of these stimuli. Thus, variation in nongustatory mechanisms is likely responsible for the strain differences in intake of nonsweet solutions. Although IMP was included as an umami stimulus, its sodiumindependent component was especially effective at driving S-cells, indicating that it may have tasted partly sweet, or at least that sweet and umami taste signals converge. However, the size of this component was similar in the two strains, and therefore it is not responsible for greater consumption of IMP by B6 than 129 mice (Bachmanov et al., 2000).

\section{Implications for gustatory coding}

Strain differences depended on the particular evoked period chosen by the experimenter. Evoked periods $<1$ s, however, proved a poor choice for providing insight into the animals' taste quality perceptions using across-neuron patterns. This is unusual, given neural (Stapleton et al., 2006) and behavioral response latencies to taste solutions in rats, which can discriminate between compounds in $<1 \mathrm{~s}$ (Halpern and Tapper, 1971; Scott, 1974). There have been no attempts to measure discrimination latencies for taste stimuli in mice, but such work will be valuable to answer whether there are discrepancies between neural and behavioral response latencies, bearing in mind possibilities such as differences in how taste receptors are stimulated in awake and anesthetized animals. This issue does not affect the usefulness of across-neuron patterns based on $5 \mathrm{~s}$ periods as a predictive measure for inferring perceived taste quality, but it will be important in determining whether such patterns form the primary neural basis for such perceptions. Other variables, such as the precise timing of spikes, may also contribute or 


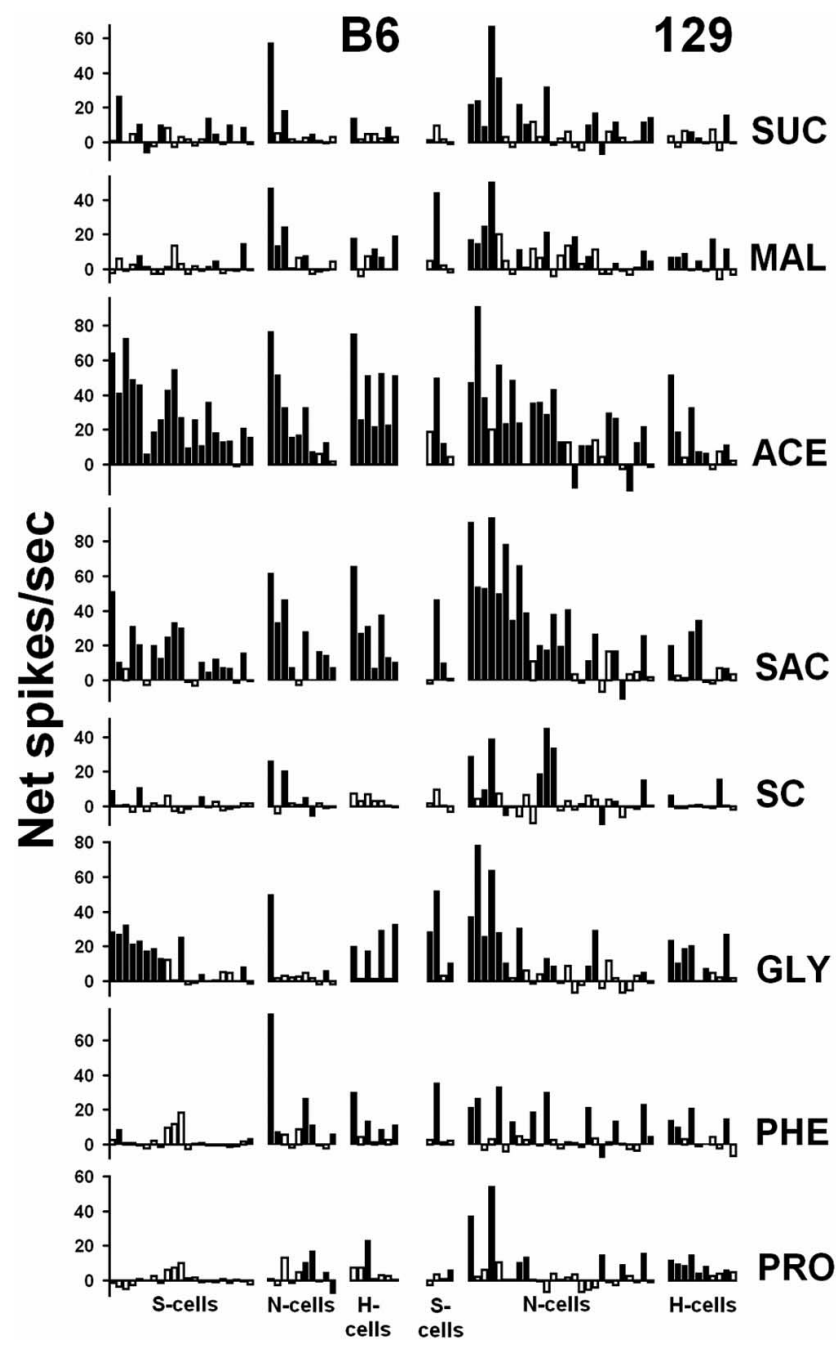

Figure 8. Across-neuron patterns displaying net responses to the eight sweeteners in individual neurons in B6 (left) and 129 (right) mice based on the first $600 \mathrm{~ms}$ after stimulus onset. Neurons are in the same order as for Figure 4 , but the particular values differ from those in Figure 4 because of the different time periods over which spikes were counted. The filled bars indicate that the response reached the criterion for significant excitation or inhibition, whereas the open bars did not. Stimuli are labeled on the right (abbreviations are as in Table 1).

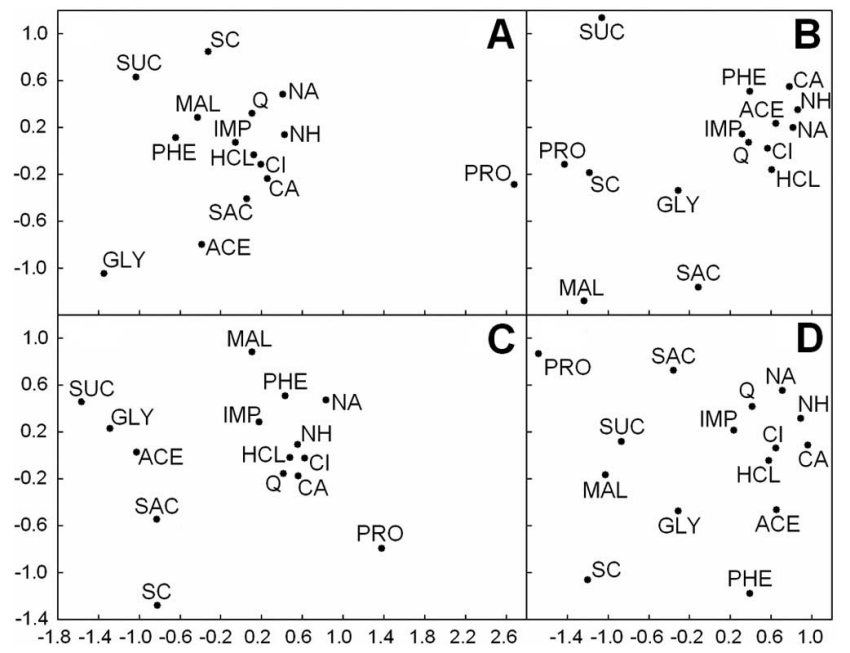

Figure 9. Two-dimensional spaces resulting from multidimensional scaling and showing the similarity of stimuli based on their across-neurons patterns of activity. Analyses are based on the number of net spikes at $600(A, B)$ or $900(C, D)$ ms after onset in $B 6(A, C)$ or $129(B, D)$ mice. Abbreviations are as in Table 1. be more important, especially during the initial response period (Di Lorenzo and Victor, 2003).

Although evidence was found for different pathways of activity in response to sweeteners, these pathways should not be confused with so-called "labeled lines" thought to convey information about sweet and bitter taste to separate populations of central gustatory neurons in mice (Sugita and Shiba, 2005). The broad tuning of NST cells observed here contradicts labeled-line coding. Furthermore, the current data are consistent not only with links between receptor binding of sweeteners and responses of NST cells, but also with complex processing of taste activity, including inhibition between subgroups of cells and a process that amplifies, but delays, responses to sweeteners.

\section{References}

Arras M, Autenried P, Rettich A, Spaeni D, Rulicke T (2001) Optimization of intraperitoneal injection anesthesia in mice: drugs, dosages, adverse effects, and anesthesia depth. Comp Med 51:443-456.

Åström KE (1953) On the central course of afferent fibres in the trigeminal, facial, glossopharyngeal, and vagal nerves and their nuclei in the mouse. Acta Physiol Scand 29 [Suppl 106]:209-320.

Bachmanov AA, Reed DR, Tordoff MG, Price RA, Beauchamp GK (1996) Intake of ethanol, sodium chloride, sucrose, citric acid, and quinine hydrochloride solutions by mice: a genetic analysis. Behav Genet 26:563-573.

Bachmanov AA, Tordoff MG, Beauchamp GK (2000) Intake of umamitasting solutions by mice: a genetic analysis. J Nutr 130 [Suppl]:935S-941S.

Bachmanov AA, Tordoff MG, Beauchamp GK (2001) Sweetener preference of C57BL/6ByJ and 129P3/J mice. Chem Senses 26:905-913.

Bachmanov AA, Beauchamp GK, Tordoff MG (2002) Voluntary consumption of $\mathrm{NaCl}, \mathrm{KCl}, \mathrm{CaCl}_{2}$, and $\mathrm{NH}_{4} \mathrm{Cl}$ solutions by 28 mouse strains. Behav Genet 32:445-457.

Chang F-CT, Scott TR (1984) Gustatory stimulus delivery in the rodent. Chem Senses 9:91-96.

Damak S, Rong M, Yasumatsu K, Kokrashvili Z, Varadarajan V, Zou S, Jiang P, Ninomiya Y, Margolskee RF (2003) Detection of sweet and umami taste in the absence of taste receptor T1R3. Science 301:850-853.

Di Lorenzo PM, Victor JD (2003) Taste response variability and temporal coding in the nucleus of the solitary tract of the rat. J Neurophysiol 90:1418-1431.

Doetsch GS, Erickson RP (1970) Synaptic processing of taste-quality information in the nucleus tractus solitarius of the rat. J Neurophysiol 33:490-507.

Dotson CD, Spector AC (2004) The relative affective potency of glycine, $\mathrm{L}$-serine and sucrose as assessed by a brief-access taste test in inbred strains of mice. Chem Senses 29:489-498.

Erickson RP (1966) Nontraumatic headholders for mammals. Physiol Behav 1:97-98.

Frank ME, Blizard DA (1999) Chorda tympani responses in two inbred strains of mice with different taste preferences. Physiol Behav 67:287-297.

Ganchrow JR, Erickson RP (1970) Neural correlates of gustatory intensity and quality. J Neurophysiol 33:768-783.

Giza BK, McCaughey SA, Zhang L, Scott TR (1996) Taste responses in the nucleus of the solitary tract in saccharin-preferring and saccharin-averse rats. Chem Senses 21:147-157.

Glendinning JI, Chyou S, Lin I, Onishi M, Patel P, Zheng KH (2005) Initial licking responses of mice to sweeteners: effects of Tas1r3 polymorphisms. Chem Senses 30:601-614.

Halpern BP, Tapper DN (1971) Taste stimuli: quality coding time. Science 171:1256-1258.

Hamilton RB, Norgren R (1984) Central projections of gustatory nerves in the rat. J Comp Neurol 222:560-577.

Heitler WJ (1999) Dataview software program. St Andrews, Scotland: University of St. Andrews.

Hof PR, Young WG, Bloom FE, Belichenko PV, Celio MR (2000) Comparative cytoarchitecture atlas of the C57BL/6 and 129/Sv mouse brains. Amsterdam: Elsevier Science.

Inoue M, McCaughey SA, Bachmanov AA, Beauchamp GK (2001) Wholenerve chorda tympani responses to sweeteners in C57BL/6ByJ and 129P3/J mice. Chem Senses 26:915-923. 
Inoue M, Reed DR, Li X, Tordoff MG, Beauchamp GK, Bachmanov AA (2004) Allelic variation of the Tas1r3 taste receptor gene selectively affects behavioral and neural taste responses to sweeteners in the $\mathrm{F}_{2}$ hybrids between C57BL/6ByJ and 129P3/J mice. J Neurosci 24:2296-2303.

Katz DB, Simon SA, Nicolelis MA (2001) Dynamic and multimodal responses of gustatory cortical neurons in awake rats. J Neurosci 21:4478-4489.

Katz DB, Nicolelis MA, Simon SA (2002) Gustatory processing is dynamic and distributed. Curr Opin Neurobiol 12:448-454.

Lemon CH, Smith DV (2006) Influence of response variability on the coding performance of central gustatory neurons. J Neurosci 26:7433-7443.

Manita S, Bachmanov AA, Li X, Beauchamp GK, Inoue M (2006) Is glycine "sweet" to mice? Mouse strain differences in perception of glycine taste. Chem Senses 31:785-793.

McCaughey SA, Tordoff MG (2001) Calcium deprivation alters gustatoryevoked activity in the rat nucleus of the solitary tract. Am J Physiol 281:R971-R978.

Nakamura K, Norgren R (1993) Taste responses of neurons in the nucleus of the solitary tract of awake rats: an extended stimulus array. J Neurophysiol 70:879-891.

Nakashima K, Katsukawa H, Sasamoto K, Ninomiya Y (2001) Behavioral taste similarities and differences among monosodium L-glutamate and glutamate receptor agonists in C57BL mice. J Nutr Sci Vitaminol (Tokyo) 47:161-166.

Nelson G, Hoon MA, Chandrashekar J, Zhang Y, Ryba NJ, Zuker CS (2001) Mammalian sweet taste receptors. Cell 106:381-390.

Nie Y, Vigues S, Hobbs JR, Conn GL, Munger SD (2005) Distinct contributions of T1R2 and T1R3 taste receptor subunits to the detection of sweet stimuli. Curr Biol 15:1948-1952.

Ninomiya Y, Funakoshi M (1989) Qualitative discrimination among "umami" and the four basic taste substances in mice. In: Umami, a basic taste (Kawamura Y, Kare MR, eds), pp 365-385. New York: Marcel Dekker.

Ninomiya Y, Mizukoshi T, Higashi T, Katsukawa H, Funakoshi M (1984a) Gustatory neural responses in three different strains of mice. Brain Res 302:305-314.

Ninomiya Y, Higashi T, Katsukawa H, Mizukoshi T, Funakoshi M (1984b) Qualitative discrimination of gustatory stimuli in three different strains of mice. Brain Res 322:83-92.

Ninomiya Y, Nomura T, Katsukawa H (1992) Genetically variable taste sensitivity to D-amino acids in mice. Brain Res 596:349-352.
Paxinos G, Franklin KBJ (2001) The mouse brain in stereotaxic coordinates, Ed 2. San Diego: Academic.

Reed DR, Li S, Li X, Huang L, Tordoff MG, Starling-Roney R, Taniguchi K, West DB, Ohmen JD, Beauchamp GK, Bachmanov AA (2004) Polymorphisms in the taste receptor gene (Tas1r3) region are associated with saccharin preference in 30 mouse strains. J Neurosci 24:938-946.

Sclafani A (2006a) Sucrose motivation in sweet "sensitive" (C57BL/6J) and "subsensitive" (129P3/J) mice measured by progressive ratio licking. Physiol Behav 87:734-744.

Sclafani A (2006b) Enhanced sucrose and Polycose preference in sweet "sensitive" (C57BL/6J) and "subsensitive" (129P3/J) mice after experience with these saccharides. Physiol Behav 87:745-756.

Scott TR (1974) Behavioral support for a neural taste theory. Physiol Behav 12:413-417.

Scott TR, Yaxley S, Sienkiewicz ZJ, Rolls ET (1986) Gustatory responses in the nucleus tractus solitarius of the alert cynomolgus monkey. J Neurophysiol 55:182-200.

Smith DV, Li CS (1998) Tonic GABAergic inhibition of taste-responsive neurons in the nucleus of the solitary tract. Chem Senses 23:159-169.

Smith DV, Travers JB (1979) A metric for the breadth of tuning of gustatory neurons. Chem Senses 4:215-229.

Smith DV, Travers JB, Van Buskirk RL (1979) Brainstem correlates of gustatory similarity in the hamster. Brain Res Bull 4:359-372.

Smith DV, Van Buskirk RL, Travers JB, Bieber SL (1983) Gustatory neuron types in hamster brain stem. J Neurophysiol 50:522-540.

Stapleton JR, Lavine ML, Wolpert RL, Nicolelis MA, Simon SA (2006) Rapid taste responses in the gustatory cortex during licking. J Neurosci 26:4126-4138

Sugita M, Shiba Y (2005) Genetic tracing shows segregation of taste neuronal circuitries for bitter and sweet. Science 309:781-785

Tanimura S, Shibuya T, Ishibashi T (1994) Neural responses of the glossopharyngeal nerve to several bitter stimuli in mice. Comp Biochem Physio Comp Physiol 108:189-194.

Travers JB, Smith DV (1979) Gustatory sensitivities in neurons of the hamster nucleus tractus solitarius. Sens Processes 3:1-26.

Verhagen JV, Giza BK, Scott TR (2003) Responses to taste stimulation in the ventroposteromedial nucleus of the thalamus in rats. J Neurophysiol 89:265-275.

Yamamoto T, Matsuo R, Fujimoto Y, Fukunaga I, Miyasaka A, Imoto T (1991) Electrophysiological and behavioral studies on the taste of umam substances in the rat. Physiol Behav 49:919-925. 